\title{
SITUATION WITH COKING COALS ON A GLOBAL SCALE. STAMP CHARGING TECHNOLOGIES AS A WAY TO IMPROVE THE SITUATION*
}

Rudolf Lesch ${ }^{1}$

\begin{abstract}
Till date, coke has been produced mainly from coals with a content of volatile matters in the range of $20 \%$ to $28 \%$ and good coking properties. If such so-called "selfcoking" coals are available, blast furnace coke or foundry coke with the required quality characteristics can be produced in top-charged horizontal ovens. In this case, the possibility of using high-volatile coals and in particular coals with low-caking properties is very restricted. Even if high-volatile coking coals have good coking properties, coke produced from such coal alone will not meet the requirements in terms of coke strength. The mechanical coke properties are influenced by the charge coal blend and the coking conditions. In this context, the bulk density of the oven charge is a decisive factor. Research and development in the field of coke production in horizontal chamber ovens aims at improving the specific oven throughput, increasing the raw material basis and introducing environmental protection technologies. The key factor, however, is to guarantee and further improve the rentability of the coke production. It is very important to reduce the cost of the charge coal to a minimum at the same time maintaining or even improving the coke quality.

Keywords: Coking coal; Stamp charging.
\end{abstract}




\section{INTRODUCTION}

Proportion of classical coking coals - Prime coking coals - constitutes only $9 \%$ of the total reserves in the world. Available quantity of prime coking coals in the world is dwindling fast. Existing coking plants have been operating on a coal blend containing not more than $40 \%$ of indigenous prime coking coals, with deteriorating effect on the coke quality. It is obvious that energy security, may potentially get an greater importance for the steel maker in the future.

It is worth to point out that coking coal was included in the list of Critical Raw Materials on the Session of the European Commission (MEMO/14/377), took place on 26 May 2014, Brussels.

Numerous efforts have been made during the last 30 years to enlarge the range of coking coal taking into account the optimization of coke output and quality.

Moreover, it became evident that the conventional chamber coking method still holds considerable possibilities of further development. This means that the addition of a supplementary procedure such as:

- an improved blending and grinding technique in connection with the utilization of auxiliary materials

- preheating

- densification of the charge coal

Although these high-volatile coals have fair or even good coking properties, they are less suited for making blast furnace coke than classical coking coals. Because of their high content of volatile matter, the loss of substance in form of gas and tar during carbonization is too high which creates internal tensions in the coke. These tensions cause a susceptibility to crack and break. Early tests in the Research Centre proved that the mechanical coke strength is a function of coal density in the coke oven.

\section{MATERIAL AND METHODS}

A stamp charged coke oven plant differs from a conventional top charged coke oven plant in the coal blend used, the preparation of the charge coal blend and in the way of oven charging. In all other aspects, a stamp charged coke oven plant is equal to a top charged coke oven plant.

Early tests in the Saarberg Research Centre proved that the mechanical coke strength is a function of coal density in the coke oven.

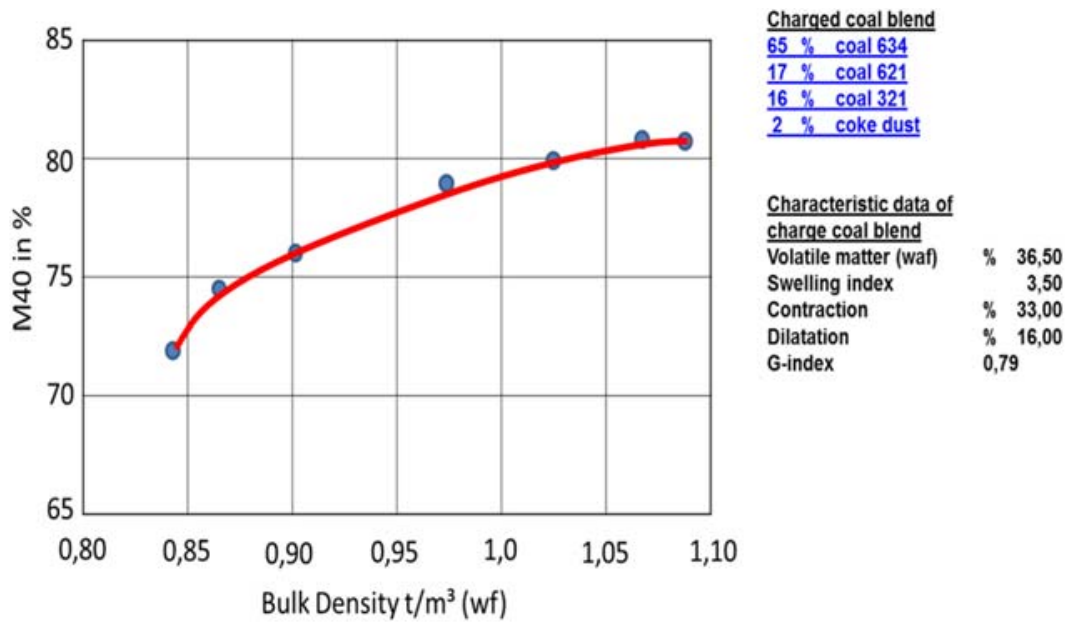

Figure 1. Mechanical coke strength is a function of coal density 
If the charge density is such an important factor, how we can achieve a high density?

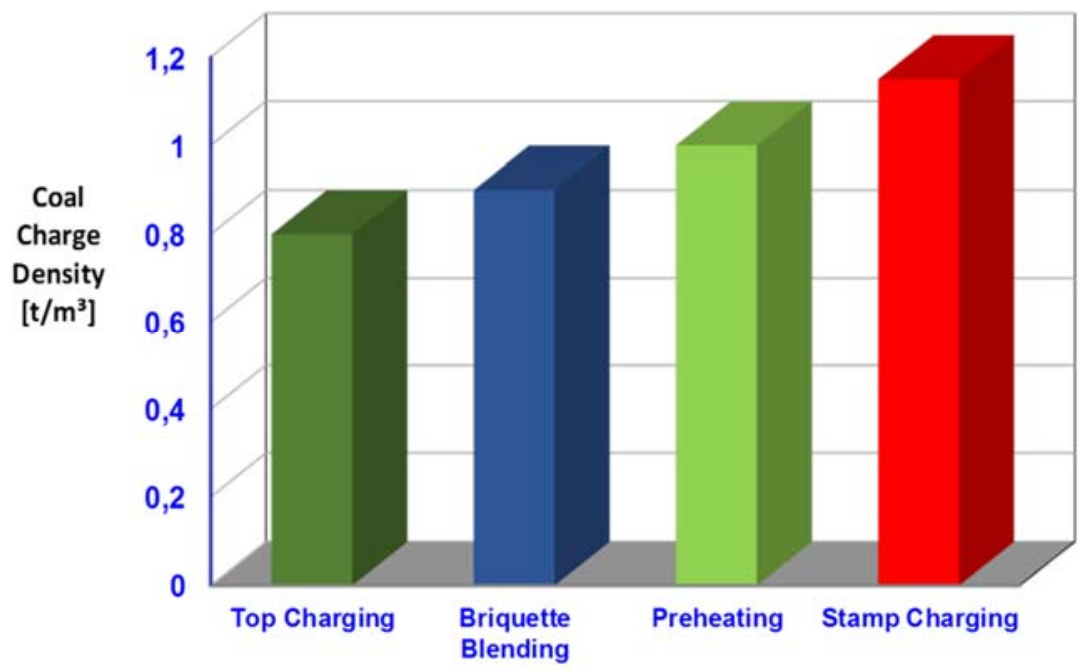

Figure 2. Coal charge density

A Stamp Charged oven filling is characterised by the highest charge density of all pre-carbonisation technologies. Employing the HUDE / Kuttner Stamping Units charge densities of $1.15 \mathrm{t} / \mathrm{m}^{3}$ or even beyond can be achieved.

Or make it simple, see the differences in coke quality:

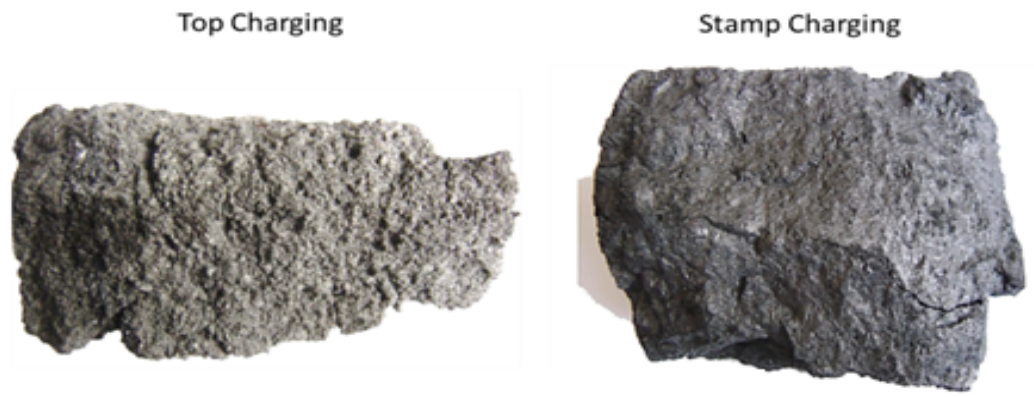

Figure 3: Same Coal Blend but different results

The Stamp Charging Technology is characterized by a high flexibility in the use of low caking and therefore cost-effective coal. It furthermore increases the coke quality and contributes to a considerable degree to the cost optimisation in integrated steel plants. 


\subsection{Stamp Technology, How Does It Works:}

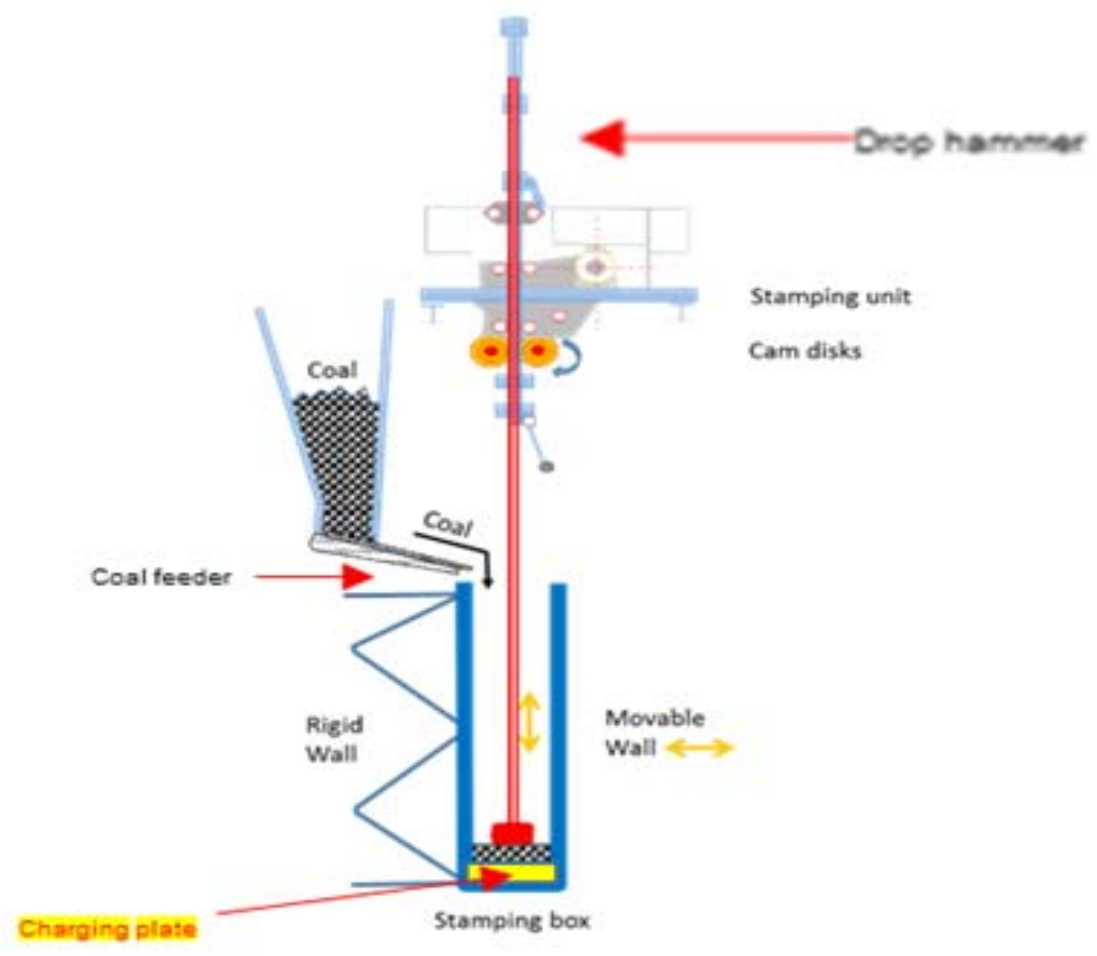

Figure 4. Stamp technology

\subsubsection{Mode of Operation}

- The coal feeders are staring and spraying a layer of coal into the stamping box. Hereby the coal will fall until the bottom of the box, means to the top of the charging plate.

- The power system of the stamping units can be switched on and the compacting procedure will start, the coal will be feed continuously in the stamping box.

- If the coal cake has reached the correct height, the stamping system will stop automatically and the drop hammers will be lifted in the home position.

- During the coal cake preparation, the pushing sequence is finished, the coke oven door as well the oven frame are cleaned and the coke is pushed out.

- The stamping box door in front of the oven moves in the "open position" and the movable wall of the stamping box moves in the open position.

- The result is that a gap between coal cake and stamping box wall exists and the stamped coal cake is standing just on the charging plate.

- The charging plate -which will be driven via roller chain and electrical motorwill charge the coal cake completely into the oven. A special unit (the charging trestle) which is installed at the back of the charging plate moves also forward and will be locked, if the coal cake is completely charged into the coke oven. After this, the charging plate will remove backwards and -if the plate is nearly pulled out under the coal cake - the charging trestle will be relocked and will be pulled back via winch. Now the charging plate moves back in its home position, the movable wall and the stamping box door will be closed and the coke oven door can be inserted. 


\subsubsection{The Coal cake's Density and the Coal cake's Stability}
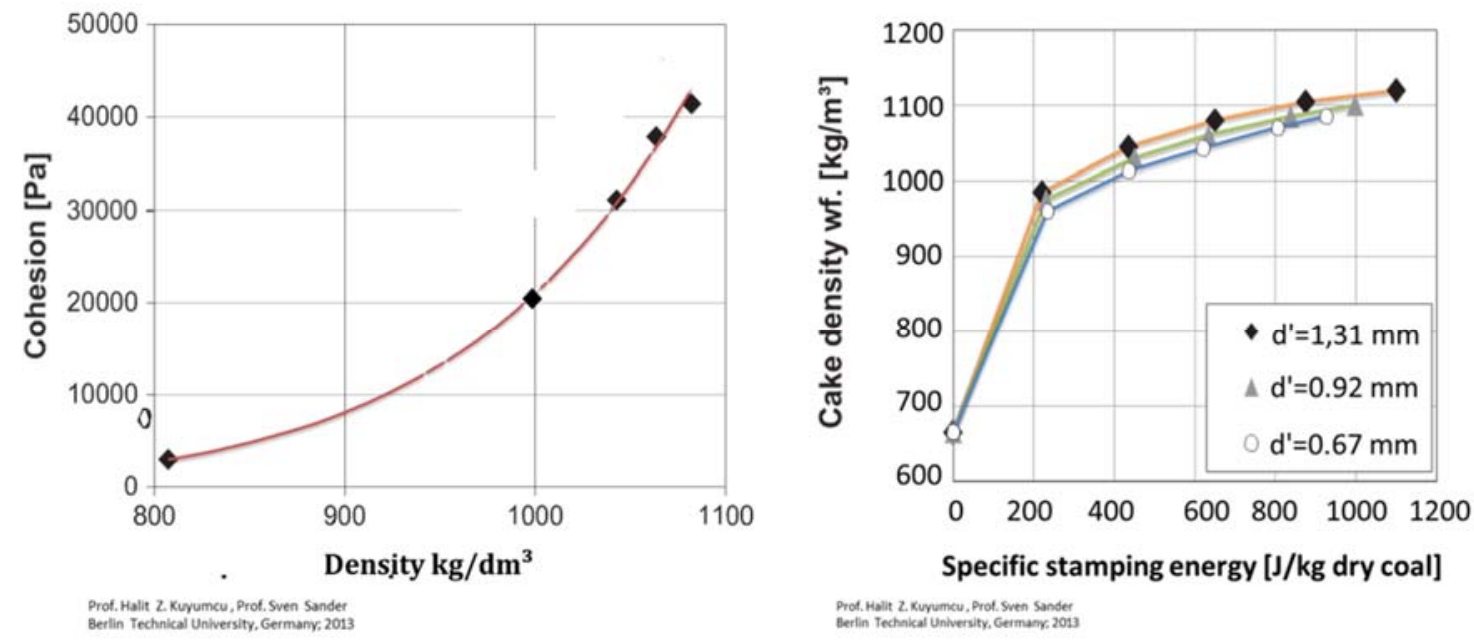

Figure 5: Relation between the coal cake's density and the coal cakes's stability

With respect to the graph above, a strong relation between the density of coal cake and coal cake stability is given. It is also obvious that for the required stamp density a specific stamping energy should be supplied.

This must keep in mind, especially by conversion Top - Charging to Stamp Charging. For this reason, HuDe / Kuttner can use drop hammers with a weight from $650 \mathrm{~kg}$ instead the normal $380 \mathrm{~kg}$ hammers.

\section{RESULTS AND DISCUSSION}

HuDe / Kuttner proposes very flexible and customized orientated solutions for implementing Stamp Charging Technology:

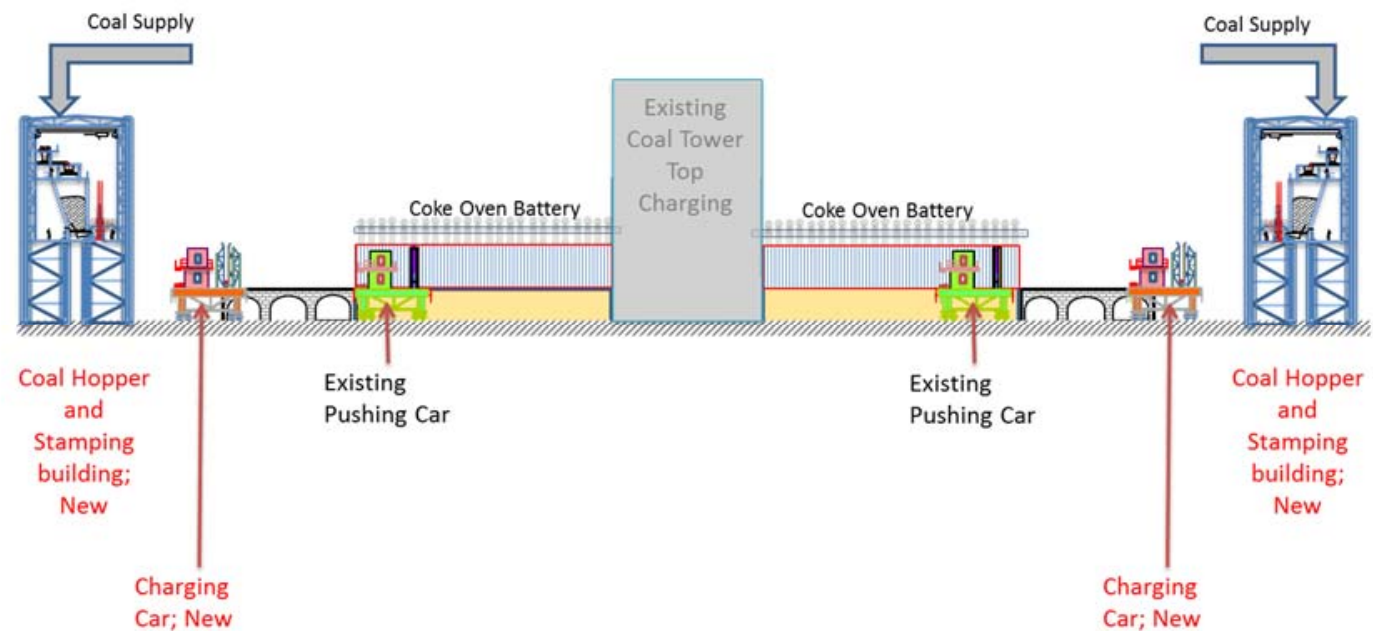

Figure 6. Individual customer solution

Installation of stamp charging facilities for existing operating coke batteries (new coal hopper with conveyor supply of coal blend, stationary stamping stations and charging cars or stamping-charging-pushing machines SCPM are installed at the pusher side of coke battery). 
Later on, when old coke battery is fully worn out and deteriorated and has to be put out of operation, a new coke battery is to be constructed on the same place but existing stamping facilities and machines are still available and there is no need for their construction. It reduces drastically investment costs and construction time. Payback period is also reduced.

Installation of stamp charging facilities for new coke batteries:

- option with stationary stamping stations and separate oven service machines;

- option with stamping-charging-pushing machines (SCPM);

- option with new coal tower and coal hopper located on SCPM;

- option with conveyor belt supply of coal blend to coal hopper of stationary stamping stations.

\section{CONCLUSION}

In their majority, the steel producers share the opinion that blast furnaces will continue, in a reasonable future, to hold their fort as most important means for iron ore reduction. Thus the coke oven plants must accept the challenge of producing a suitable coke of appropriate quality at reasonable prices.

Based on the assumption that approx. $70 \%$ of the cost for coke is spent for charge materials, the possibilities of using inexpensive blending components should be given priority. Therefore, in the future coke oven plants should make use of those technologies which allow a substantial reduction of the portion of relatively shortrunning and expensive prime coking coals.

Due to the high density of the coal charge achieved by stamp charging, this technology allows a high flexibility in the range of charge materials. This technology allows to take profit of the advantages of high-volatile, low-caking and inexpensive charge materials for the production of blast furnace coke with good mechanical properties at reasonable prices.

\section{REFERENCES}

1 Prof.Halit Z. Kuyumcu, Prof Sven Sander Berlin Technical University, Germany; 2013. 